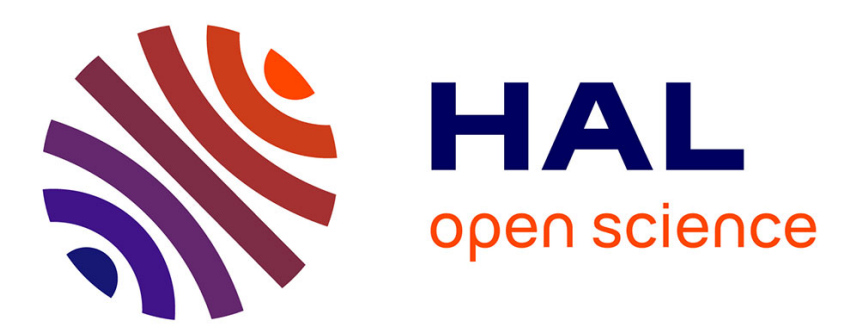

\title{
Bioaccumulation of perfluoroalkyl compounds in midge (Chironomus riparius) larvae exposed to sediment
}

\author{
D. Bertin, B. Ferrari, P. Labadie, A. Sapin, J. Garric, H. Budzinski, M. \\ Houde, M. Babut
}

\section{- To cite this version:}

D. Bertin, B. Ferrari, P. Labadie, A. Sapin, J. Garric, et al.. Bioaccumulation of perfluoroalkyl compounds in midge (Chironomus riparius) larvae exposed to sediment. Environmental Pollution, 2014, 189, p. 27 - p. 34. 10.1016/j.envpol.2014.02.018 . hal-01058508

\section{HAL Id: hal-01058508 \\ https://hal.science/hal-01058508}

Submitted on 27 Aug 2014

HAL is a multi-disciplinary open access archive for the deposit and dissemination of scientific research documents, whether they are published or not. The documents may come from teaching and research institutions in France or abroad, or from public or private research centers.
L'archive ouverte pluridisciplinaire HAL, est destinée au dépôt et à la diffusion de documents scientifiques de niveau recherche, publiés ou non, émanant des établissements d'enseignement et de recherche français ou étrangers, des laboratoires publics ou privés. 


\section{Bioaccumulation of perfluoroalkyl compounds in midge (Chironomus riparius) larvae exposed to sediment}

Delphine Bertin ${ }^{1 *}$, Benoît J.D. Ferrari ${ }^{1,4}$, Pierre Labadie ${ }^{2}$, Alexandre Sapin ${ }^{1}$, Jeanne Garric ${ }^{1}$, Hélène Budzinski², Magali Houde ${ }^{3}$, Marc Babut ${ }^{1}$.

${ }^{1}$ Present address: IRSTEA, UR MALY, 5 rue de la Doua, CS 70077, F- 69626 Villeurbanne, France.

E-mail address : delphine.bertin@irstea.fr; benoit.ferrari@irstea.fr; alexandre.sapin@irstea.fr; jeanne.garric@irstea.fr; marc.babut@irstea.fr

2 : Université Bordeaux 1, Environnements et Paléoenvironnements Océaniques et Continentaux (EPOC), UMR 5805 CNRS, Laboratoire de Physico- et Toxico-Chimie de l'environnement (LPTC), 351 cours de la Libération, 33405 Talence, France.

E-mail address : pierre.labadie@u-bordeaux1.fr; h.budzinski@epoc.u-bordeaux1.fr

3 : Environment Canada, Aquatic Contaminant Research Division, 105 rue McGill, Montreal, QC, H2Y 2E7, Canada.

E-mail address : $\underline{\text { Magali.Houde@ec.gc.ca }}$

${ }^{4}$ : Present address: Centre Ecotox/Oekotoxzentrum, EPFL-ENAC-IIE-GE, Station 2 (GR B0 392), 1015 Lausanne, Suisse. benoit.ferrari@ centreecotox.ch

*Corresponding author: Delphine BERTIN, IRSTEA, UR MALY, 5 rue de la Doua, CS 70077, F-69626 Villeurbanne, France. delphine.bertin@ irstea.fr, phone : +33 (0)4 722010 75. 


\section{Abstract}

2 Midge larvae (Chironomus riparius) were exposed to sediments from a deposition

3 sampled at a site along the Rhône River (France) downstream of an industrial site

4 releasing various perfluorinated chemicals. This sediment is characterized by high

5 concentrations of perfluoroundecanoic acid (PFUnA) and perfluorotridecanoic acid

6 (PFTrDA) and a low perfluorooctane sulfonate (PFOS) concentration. Concentrations

7 of 23 perfluoroalkyl compounds, including $\mathrm{C}_{4}-\mathrm{C}_{14}$ carboxylate acids, $\mathrm{C}_{4}-\mathrm{C}_{10}$ sulfonates,

8 and seven precursors, were analyzed in overlying and pore water, sediment, and larvae.

9 Midge larvae accumulated carboxylate acids $\left(\mathrm{C}_{11}-\mathrm{C}_{14}\right)$, PFOS, and two precursors

10 (perfluorooctane sulfonamide: FOSA and 6:2 fluorotelomer sulfonic acid, 6:2 FTSA).

11 These substances accumulated mainly during the fourth instar larvae exponential growth

12 phase. Accumulation of 6:2 FTSA, PFUnA, and PFOS occured via trophic and

13 tegumentary routes. Other compounds mainly accumulated from food. Kinetics

14 followed a partition model, from which uptake and elimination constants were derived.

16 Keywords: Perfluoroalkyl compounds, sediment, Chironomus riparius,

17 bioaccumulation.

19 Capsule: Chironomus riparius mainly bioaccumulates long-chain PFASs via trophic

20 and/or tegumentary routes during the fourth instar larvae growth phase.

\section{Introduction}

Polyfluoroalkyl and perfluoroalkyl substances (PFASs) have been produced

24 since the early 1950s. The production and use of these compounds have resulted in their 
global distribution in the environment (Houde et al., 2011; Houde et al., 2006;

26 Prevedouros et al., 2006). In 2000, the 3M company voluntarily phased -out $\mathrm{C}_{8}$-based-

27 chemicals (i.e., sulfonamide based polymers), at the base of the formation of

28 perfluorooctane sulfonate (PFOS) and perfluorooctanoic acid (PFOA), and replaced

29 them with shorter- chain chemicals (e.g., perfluorobutane sulfonate, PFBS) (Renner,

30 2006; Lindstrom et al., 2011). In 2009, PFOS was listed under Annex B of the

31 Stockholm convention (United Nations Environmental Program -UNEP) on Persistent

32 Organic Pollutants (POPs) (Lindstrom et al., 2011).

PFASs have been found in all aquatic media (Houde et al., 2011; Houde et al., 2006). On the basis of global modelling, marine sediments have been designated as the ultimate containment for PFASs (Armitage et al., 2006). Several studies have shown the presence of PFASs in sediment with concentrations ranging from $0.5 \pm 0.1$ to $38.3 \pm$ 16.8 ng.g ${ }^{-1}$ dw (Ahrens et al., 2009; Bao et al., 2009; Bao et al., 2010; Higgins et al., 2005; Labadie and Chevreuil, 2011; Myers et al., 2012; Zushi et al., 2010). Sediment has been suggested as a major source of contamination of aquatic organisms (Martin et al., 2004). However, the distribution of water, sediment, and biota as well as the role of the sediment compartment in biota contamination is still poorly understood. The length of the fluorocarbon chain is an important criterion for PFAS distribution in the environment (Ahrens et al., 2009; Higgins and Luthy, 2006; Myers et al., 2012). PFASs with eight or more carbon atom backbones are known to be bioaccumulative (Kannan et al., 2005; Kelly et al., 2009; Loi et al., 2011; Tomy et al., 2004). al., 2012). Highest levels of PFASs were found in fish from this latter river (mean total PFAS concentration: 241.5 ng. ${ }^{-1}$ dry weight (dw)), the Rhône River was therefore 
49 chosen as the study site for this research which aimed to better understand the origin of

50 PFAS contamination in aquatic organisms by evaluating the transfer of these

51 compounds from sediment to invertebrates.

A benthic invertebrate, the non-biting midge Chironomus riparius, is found in

sediment from the Rhône River and is recommended by the OECD for toxicity testing

54 (OECD, 2004). Midges are holometabolous, that is they go through complete

metamorphosis consisting of egg, larva, pupa, and adult stages. C. riparius mates in

aerial swarms. After mating, the female deposits the eggs on the water surface. Larvae

undergo four instars; the first (L1) is planktonic and the second to fourth larval stages

(L2, L3, L4) are in direct contact with sediment (Fig. S1). Larvae L2 to L4 are collector-

gatherers, feeding mainly on detritus and its associated bacteria and fungi. This species the bioaccumulation of perfluoroalkyl compounds (Armitage et al., 1995).

riparius larvae and (ii) to describe the kinetics of the bioaccumulation process.

\section{Materials and Methods}

70 fluoropolymer manufacturing plant that has been found to be an important source of 
74 Veen grab, kept on ice and brought to the laboratory, where they were sieved at $2 \mathrm{~mm}$, pooled in a polypropylene $(\mathrm{PP}) \mathrm{jar}$, and stored at $4^{\circ} \mathrm{C}$. Six aquaria $(38 \times 20 \times 24.5 \mathrm{~cm}$ in polystyrene) were prepared with $4 \mathrm{~L}$ of homogenized sediment and $15 \mathrm{~L}$ of groundwater mixed with treated water via an osmosis system in order to reach a conductivity of 300 $\mu \mathrm{S} . \mathrm{cm}^{-1}$. Each aquarium was allowed to settle for 1 week before introducing the chironomids. Three control aquaria were prepared in the same manner with silica sand (particle size distribution: 90\% 50-200 $\mu \mathrm{m}, 10 \%<50 \mu \mathrm{m}$ ) (Péry et al., 2002). The sediment was characterized for water content, nitrogen, carbonate using a

82 Bernard calcimeter, and loss on ignition (LOI) (AFNOR, 1994, 2000, 2007; Vatan

83 1967) and showed a water content of $43.4 \%$, an organic carbon content of $4.3 \%$, a carbonate content of $27.4 \%$, and a nitrogen content of $0.19 \%$. The particle size distribution was determined by laser diffractometry (Cilas 1190, France) and found to be $10 \%$ clay -silt $(<5.83 \mu \mathrm{m}), 40 \%$ silt $(5.83-52.24 \mu \mathrm{m})$, and $50 \%$ of silt -very fine 87 sand $(>52.24 \mathrm{~mm})$.

\subsection{C. riparius exposure}

Chironomids were obtained from laboratory cultures made according to standard methods (AFNOR, 2010; OECD, 2004). Chironomids were exposed to the BER sediment at standard temperature $\left(21^{\circ} \mathrm{C}\right)$. Two experiments were conducted to examine

92 the extent to which developmental stage influences the amount of accumulated

93 chemicals in C. riparius (experimental designs shown in Fig. S2). The first experiment

94 (E1) started with L2 larvae until the end of the L4 stage and lasted for 9 days. The second experiment (E2) started directly with L4 larvae. 
97 to three study aquaria, and to three control aquaria (400 in each aquarium). In experiment E2, 1200 early L4 larvae (7-day-old larvae post-hatching) were exposed in three aquaria. Overlying water (OW) was continuously renewed (four times a day) to

100 maintain adequate water quality and oxygenated under a 16:8-h light: dark photoperiod

101 during the experiment. Larvae were fed ad libitum each day with $1 \mathrm{mg}$ commercial food

$102\left(\right.$ Tetramin $\left.^{\circledR}\right)$ per organism per day. We decided to feed the chironomids during the experiment because previous experiments showed that larvae did not survive without an external supply of food in this sediment. A quantity of $1 \mathrm{mg}$ Tetramin ${ }^{\circledR}$ per organism per day was selected because preliminary tests (data not shown) conducted with $0.6 \mathrm{mg}$

106 Tetramin $^{\circledR}$ per organism per day showed low survival and growth. E1 organisms were sacrificed after 11 post-hatching days, i.e., 9 days (Tfinal, Tf) after being introduced in the aquaria. E2 organisms were sacrificed at 2 (T1), 3 (T2), and 4 (T3) days, respectively, after introducing $\mathrm{L} 4$ chironomids. The water quality parameters $(\mathrm{pH}$,

110 concentration of dissolved oxygen, conductivity, $\mathrm{NO}_{2}^{-}$, and $\mathrm{NH}_{4}^{+}$) were monitored once 111 a week and at the beginning and the end of the exposure period (Fig. S2).

114 T3, and Tf. E1 organisms were sampled only at Tf. E2 chironomids were sampled at T0

115 (fourth instar larvae), T1, T2 and T3, and Tf. The overlying water was sampled directly

116 in a $1 \mathrm{~L}$ polyethylene (PE) bottle. For pore water, we used a Rhizon ${ }^{\circledR}$ system (SDEC,

117 Reignac-sur-Indre, France), which consists of one porous polymer part inside a

118 fiberglass rod. Organisms were collected by sieving the upper layer of sediment at

$119500 \mu \mathrm{m}$; sub-samples from deeper sediment were deposited in PE tubes. Organisms were 
120 split into two different batches for PFAS analysis (about $800 \mathrm{mg} \mathrm{ww}$, representing

121 about 200 larvae) and $\delta^{13} \mathrm{C}$ and $\delta^{15} \mathrm{~N}$ isotopic analysis (about $5 \mathrm{mg} \mathrm{dw}$ of larvae). Biota

122 samples were cryopreserved in liquid nitrogen and stored at $-21^{\circ} \mathrm{C}$ and abiotic samples

123 frozen and kept at $-21^{\circ} \mathrm{C}$ (Fig S2).

124 Chironomid survival, length, and weight were determined for all aquaria. To determine

125 length, four groups of ten larvae were photographed and mean sizes assessed using

126 digital image analysis software (Jmicrovision, freely available via

127 http://www.jmicrovision.com/). The same groups were then weighed (weighing scales:

128 Sartorius CPA225D, France) to obtain mean weights.

\subsection{PFAS extraction}

$130 \quad$ 2.4.1 Overlying and pore water samples

Water samples were each spiked with 2 ng of IS and processed using Srata X-

132 AW cartridges as described by Labadie and Chevreuil (2011).

133 Eluates were concentrated to $400 \mu \mathrm{L}$ under a nitrogen stream at $40^{\circ} \mathrm{C}$ and transferred

134 into PP vials (final volume: $250-300 \mu \mathrm{L}$ ). Extracts were stored at $-20^{\circ} \mathrm{C}$ until analysis.

$135 \quad$ 2.4.2 Sediment sample

136 Sediment samples were extracted by sonication, using a method adapted from

137 Sun et al. (2011). Samples (1 g dw) were spiked with ISs (1.8 ng each) and extracted

138 with $5 \mathrm{~mL}$ of $\mathrm{MeOH}$ for $20 \mathrm{~min}$, prior to centrifugation for $3 \mathrm{~min}\left(20^{\circ} \mathrm{C}, 2900 \mathrm{~g}\right)$. This

139 procedure was repeated with $2.5 \mathrm{~mL}$ of $\mathrm{MeOH}$ and the two extracts were combined and

140 concentrated to $800 \mu \mathrm{L}$ under a nitrogen stream at $40^{\circ} \mathrm{C}$. Samples were purified using

141 ENVI-Carb cartridges previously conditioned with $4 \mathrm{~mL}$ of $\mathrm{MeOH}$ and eluted with $2 \times 4$

$142 \mathrm{~mL}$ of $\mathrm{MeOH}$. Eluates were concentrated to $400 \mu \mathrm{L}$ under a nitrogen stream at $40^{\circ} \mathrm{C}$ and

143 transferred into injection vials. 
$144 \quad 2.4 .3$ C. riparius samples and Tetramin ${ }^{\circledR}$ samples

145 Extraction of PFASs in $120 \mathrm{mg} \mathrm{dw}$ C. riparius (800 $\mathrm{mg}$ wet weight (ww)) and in

$146540 \mathrm{mg}$ Tetramin ${ }^{\circledR}$ followed the same protocol used for the sediment samples. Extract

147 clean-up was adapted from Ballesteros-Gomez et al. (2010). Extracts were diluted 20

148 times with ultra-pure water (5\% extract in water) and then passed through a Strata X-

149 AW cartridge previously conditioned as described above. After extract loading,

150 cartridges were washed with $5 \mathrm{~mL}$ of sodium acetate buffer $(\mathrm{pH}=4.5,25 \mathrm{mM})$. They

151 were vacuum-dried (30-40 min) and connected via a polyethylene adaptor cap to an

152 ENVI-Carb cartridge previously conditioned with $8 \mathrm{~mL}$ of $\mathrm{MeOH}$. Neutral PFASs were

153 eluted with $8 \mathrm{~mL}$ of $\mathrm{MeOH}$ (fraction A). The ENVI-Carb cartridge was then replaced

154 and a second fraction (fraction B) containing acidic analytes was eluted with $8 \mathrm{~mL}$ of

$155 \mathrm{MeOH}$ containing $0.2 \% \mathrm{NH}_{4} \mathrm{OH}$. Fraction A eluates were concentrated to $300 \mu \mathrm{L}$ and

156 then transferred into PP injection vials. Fraction B eluates were processed almost to

157 dryness before adding $200 \mu \mathrm{L}$ of acetonitrile and $200 \mu \mathrm{L}$ ultrapure water. Extracts were

158 then passed through MeOH-rinsed centrifuge tube filters and transferred into PP

159 injection vials.

2.5 Isotopic analysis

161 Isotopic analysis $\left({ }^{13} \mathrm{C}\right.$ and $\left.{ }^{15} \mathrm{~N}\right)$ was performed by the INRA-Nancy laboratory

162 (PTEF-isotopy pole, France) on decarbonated sediment, Tetramin ${ }^{\circledR}$, and chironomids

163 (i.e., chironomids that have eliminated their gut content following $48 \mathrm{~h}$ in a beaker

164 containing silicate, overlying water with food, and chironomids with gut content). 
167 Technologie, Massy, France) interfaced with an Agilent 6460 triple quadrupole mass 168 spectrometer (details in Table S2). deviation below $15 \%$ (Table S3). $135 \%$ for the different matrices. Replicate procedural blanks were analyzed for each series of samples. The predominant compounds in surface water blanks were PFHpA

177 (mean level: $166 \mathrm{pg}$ ) and PFHxA (115 pg). For solid samples, the prevailing analytes in

180 defined as three times the standard deviation, and the limits of quantification (LQs)

181 were set at ten times the standard deviation of the blank. For analytes not detected in the blanks, LDs and LQs were determined as the concentration with a signal-to-noise ratio

184 (sediment and C. riparius) and 2-3 pg.L -1 $^{-1}$ Vittel $^{\circledR}$ mineral water samples) (Table S4).

\subsection{Data processing}

186 Data were analyzed using the Student' $t$-test. All data were checked for normality and 187 homogeneity of variance using the Shapiro-Wilk test and the Bartlett test, respectively.

188 For all statistical tests, the significance level (alpha) was set at 0.05 and calculations 
189 were performed using the software package R (version 2.11.0) (R Development Core

190 Team, 2013). For calculating data below the LQ, 0.5*LQ was used.

191 When relevant, accumulation data were fit to an exponential rise model (Eq.1)

192 with Sigma Plot 10.0 software (Systat software Inc., Point Richmond, CA, USA-

193 www.systat.com).

$$
C_{\text {org }}(\mathrm{t})=a \cdot\left(1-e^{-b t}\right) \quad \text { Eq. }(1)
$$

195 Where $\mathrm{C}_{\text {org }}$ is the concentrations in chironomids (ng. $\left.\mathrm{g}^{-1} \mathrm{ww}\right), \mathrm{t}$ the time in (h), $\mathrm{a}$ and $\mathrm{b}$ 196 are defined in the discussion.

197 This model has been adapted to existing bioaccumulation models, including the model

198 described by Spacie and Hamelink (1985) and Landrum (Landrum, 1989).

199

200

201

202

203

204

205

206

207

\section{Results}

3.1 PFAS distribution in water, sediment, food, and C. riparius Short- (PFBA to PFHxA) and long-chain PFCAs (PFOA, PFNA, PFDA, PFUnA, and PFTrDA), short- and long-chain PFSAs (PFBS, PFHxS, and PFOS) and one precursor (6:2 FTSA) were detected in OW test aquaria. PFBA, PFPA, PFHxA, PFNA, PFDA, PFBS, PFHxS, and PFOS were also detected in OW control aquaria, at levels comparable to those observed in test aquaria. Concentrations were consistent throughout the replicates (test and control) (Table S5). The same compounds were observed in pore water, except PFDA and PFTrDA; PFHpA was also measured in this compartment. In PW samples from control aquaria, PFBA, PFPA, PFHxA, PFHpA, and PFHxS were detected at levels lower than PW from test aquaria $(n=3, p$-value $<0.001)$. In sediment, short- (PFBA to PFHpA) and long-chain (PFOA to PFTeDA) PFCAs, PFOS, and two precursors (6:2 FTSA and FOSA) were detected > LQs and EtFOSAA were detected < LQs. Concentration of long-chain PFCAs were higher in sediment: 
213 PFTrDA $\left(2.54 \pm 0.23\right.$ ng. $\left.\mathrm{g}^{-1} \mathrm{dw}\right), \operatorname{PFUnA}\left(1.70 \pm 0.22 \mathrm{ng} \cdot \mathrm{g}^{-1} \mathrm{dw}\right), \operatorname{PFDoA}(1.54 \pm 0.63$

214 ng. $\left.\mathrm{g}^{-1} \mathrm{dw}\right)$, PFTeDA and PFDA $\left(0.99 \pm 0.58 \mathrm{ng} \cdot \mathrm{g}^{-1} \mathrm{dw}\right.$ and $0.91 \pm 0.43 \mathrm{ng} \cdot \mathrm{g}^{-1} \mathrm{dw}$

215 respectively), whereas PFOS was lower $\left(0.26 \pm 0.02 \mathrm{ng} \cdot \mathrm{g}^{-1} \mathrm{dw}\right)$. In sediment control

216 samples, only PFPA and PFOA results were between LDs and LQs; the other

217 compounds were $<$ LDs.

218 The analysis of Tetramin ${ }^{\circledR}$ indicated the presence of 4 PFASs: PFNA $(0.20 \pm$

$\left.2190.05 \mathrm{ng} \cdot \mathrm{g}^{-1} \mathrm{dw}\right)$, PFUnA $\left(0.34 \pm 0.32 \mathrm{ng} \cdot \mathrm{g}^{-1} \mathrm{dw}\right)$, PFOS $\left(1.43 \pm 0.17 \mathrm{ng} \cdot \mathrm{g}^{-1} \mathrm{dw}\right)$, and

220 FOSA $\left(0.39 \pm 0.03 \mathrm{ng} \cdot \mathrm{g}^{-1} \mathrm{dw}\right)$. The range of PFAS concentrations in chironomids at the

221 end of E1 and E2 exposures are presented in Table 1, PFAS concentrations in

222 chironomids control were <LDs.

223

3.2 Growth and accumulation kinetics

Survival throughout the experiments (E1 and E2) was greater than $80 \%$.

225 Chironomid weight was significantly different $(p<0.001)$ between growth in sediment

226 (two at fourth instar larvae: $7.15 \pm 0.60 \mathrm{mg}$ ) and in silica $(5.84 \pm 0.83 \mathrm{mg}$ ) at 11 days

227 post-hatching (Fig. S3). However, no adverse effect of contaminated sediment on

228 chironomid growth was observed. In addition, fourth instar larvae weight data (E2) fit

229 an exponential growth curve well $\left(\mathrm{R}^{2}=0.999, p<0.0001\right)$; growth rate $(g) 0.0148( \pm$

$230 \quad 0.0001)$.

231 The results indicated that $C$. riparius accumulated four long-chain PFCAs (> 10

232 carbons: PFUnA, PFTrDA, PFDoA, and PFTeDA), PFOS, one precursor (FOSA), and

233 one fluorotelomer (6:2 FTSA); the other compounds were all <LDs (Fig. 2). Fourth

234 instar chironomid larvae accumulated PFASs as early as the second day of exposure and

235 a steady state was observed at the end of exposure for most of the accumulated

236 compounds, except for PFTeDA (LD< PFTeDA concentration $<$ LQ) and perhaps for 
6:2 FTSA. No differences in accumulation were observed between organisms exposed only at the fourth instar and those exposed from the second to the fourth instar (Fig. 3,

239 Table 1).

241 content estimation was based on Brooke et al. (1996). According to this calculation

242 there was no difference in PFAS concentrations between chironomids in which gut

243 content was or was not estimated. Therefore, the data without gut content correction

244 were kept for further interpretation.

246 calculated according to (Higgins et al., 2007):

$\mathrm{BSAF}_{\mathrm{ww}}=\mathrm{C}_{\mathrm{org}} / \mathrm{C}_{\mathrm{sed}, \mathrm{oc}}$

where $\mathrm{C}_{\text {org }}$ (ng. $\left.\mathrm{g}^{-1} \mathrm{ww}\right)$ is the PFAS concentration in the organism (at steady state) and carbon content (Table 2).

\subsection{Isotopic analysis}

$\delta^{13} \mathrm{C}$ signatures of $-27.57 \pm 0.005 \%$ and $-23.11 \%$ and $\delta^{15} \mathrm{~N}$ signatures of $4.12 \pm$

$0.64 \%$ and $7.58 \%$ were found in sediment and chironomid food (Tetramin ${ }^{\circledR}$ )

\section{Discussion}


261 with the data reported in the literature (Table S6). This pattern of PFAS contamination may be characteristic of the upstream industrial discharge from a fluoropolymer and polyvinylidene fluoride facility (Dauchy et al., 2012). In most published studies from

264 other sites, PFUnA and PFDA were usually below $1 \mathrm{ng} . \mathrm{g}^{-1} \mathrm{dw}$ (Clara et al., 2009;

265 Higgins et al., 2005; Higgins et al., 2007; Labadie and Chevreuil, 2011), except for the

266 Coosa River in Alabama (3.80 ng. ${ }^{-1} \mathrm{dw}$ ) and Tennessee, USA (4.66 ng. $\mathrm{g}^{-1} \mathrm{dw}$ ) (Lasier et al., 2011). Detection of other long-chain PFCAs was scarce: a maximum value of 1.19 ng. $\mathrm{g}^{-1} \mathrm{dw}$ for PFTrDA was reported in Tokyo Bay, Japan (Zushi et al., 2010), and PFDoA and PFTeDA values were below $1 \mathrm{ng} \cdot \mathrm{g}^{-1} \mathrm{dw}$ in the Orge River (near Paris,

270 France) (Labadie and Chevreuil, 2011), whereas in the Coosa River, USA,

271 concentrations above $1 \mathrm{ng} \cdot \mathrm{g}^{-1} \mathrm{dw}$ (1.7 and $4.64 \mathrm{ng} \cdot \mathrm{g}^{-1} \mathrm{dw}$ respectively) were found

272 (Lasier et al., 2011). For PFOS, BER sediment concentrations (0.247 - 0.294 ng.g $\left.\mathrm{g}^{-1} \mathrm{dw}\right)$

273 were in the same range as reported in other studies around the world (Table S6) (Bao et

274 al., 2009; Benskin et al., 2012; Nakata et al., 2006) and lower than PFOS levels in the

275 Orge River (France), Coosa River (USA), Sydney Harbor (Australia), and the North and

276 Baltic Seas (Labadie and Chevreuil, 2011; Lasier et al., 2011; Theobald et al., 2012;

277 Thompson et al., 2011).

278 Comparison of the respective concentration ranges for the PFASs measured in

279 control and test aquaria make it possible to design a conceptual diagram of PFASs

280 transport between compartments (Fig. 4). Since PFBA, PFPA, PFHxA, PFNA, PFDA,

281 PFBS, and PFHxS display the same concentrations on overlying waters in control and

282 test aquaria, we inferred that sediment is not a source for these compounds to water.

283 Conversely, PFUnA, PFTrDA, and 6:2 FTSA, which were present only in OW test

284 aquaria and therefore were clearly released from the sediment. Similarly, PFBA, PFPA, 
285 PFHxA, PFOA, PFNA, PFUnA, PFOS, and 6:2 FTSA associated with test sediments were in much higher concentrations in PW from test aquaria than in PW from controls.

287 Therefore, their presence in PW cannot be related to OW. PFNA and PFOS were 288 measured in both food $\left(\right.$ Tetramin $\left.^{\circledR}\right)$ and OW controls aquaria. As a consequence, it 289 could not be exclude that PFNA and PFOS in Tetramin ${ }^{\circledR}$ were dissolved into OW.

290 However, all the PFASs measured were <LD in control chironomids; therefore

291 Tetramin ${ }^{\circledR}$ is not a source of PFASs. PFUnA, PFOS, and 6:2 FTSA were present in 292 sediment, PW, and chironomids: both PW (respiration) and sediment (food) contribute 293 to the contamination. Conversely, PFDoA, PFTrDA, PFTeDA, and FOSA present only 294 in sediment and chironomids contributed to the contamination by the ingestion of 295 sediment particles. precursors. Among these, 6:2 FTSA was found to bioaccumulate poorly in fish and rats (DuPont, 2008). Reported concentrations were generally higher for benthic

300 invertebrates than chironomids, especially for PFOS; ranges of PFOS in Capitellidae 301 and Nereidae were $0.82-12.6 \mathrm{ng} . \mathrm{g}^{-1} \mathrm{ww}$ and $0.26-0.67 \mathrm{ng} \cdot \mathrm{g}^{-1} \mathrm{ww}$ (Loi et al., 2011).

302 Mean PFAS concentrations reported for lugworm were $0.41 \mathrm{ng} \cdot \mathrm{g}^{-1} \mathrm{ww}$ (Nakata et al., 303 2006) and $280 \pm 33$ ng.g ${ }^{-1}$ ww for Diporeia hoyi (Martin et al., 2004). The latter study 304 also reported that concentrations of PFUnA, PFDoA, PFTrDA, and PFTeDA were 305 higher in Diporeia hoyi than in chironomids (Martin et al., 2004). In Nereidae and 306 Capillidae worms, concentrations of PFUnA were lower than in chironomids (Loi et al., 307 2011). Compared to chironomids from the present study, lower concentrations were also 308 reported for PFDoA in Capillidae (Loi et al., 2011), for PFOS in clams (Nakata et al., 
309 2006; Nania et al., 2009), for FOSA in clams and lugworms (Nakata et al., 2006), and

310 for PFTeDA in Nereidae worms (Loi et al., 2011). However, comparisons between

311 freshwater and marine organisms should be interpreted with caution because salt may

312 affect the chemical activity (Jeon et al., 2010a; Jeon et al., 2010b).

\subsection{Accumulation kinetics}

FOSA $>$ PFTrDA $>$ PFOS $>$ PFUnA $>6: 2$ FTSA $>$ PFTeDA $>$ PFDoA, and no trend

et al. (2011) reported that BSAF values increased with increasing chain length. BSAF

and Lasier et al. (2011) (e.g., PFUnA BSAF ${ }_{\mathrm{ww}}$ chironomid $=0.020 ; \mathrm{BSAF}_{\mathrm{ww}}=0.44 \pm$

$0.11 ; \mathrm{BSAF}_{\mathrm{ww}}=0.29, \mathrm{CV}=40$, respectively). This might be explained by the fact to the

324 decrease the exposure and dilute the contamination because without this addition the chironomids would have fed only on sediment organic matter. Our experiment was low when no food was added to the aquaria. for PFOA and PFDS but not for PFNA, PFOS, PFDA, PFUnA, and PFDoA. In this experiment $C$. riparius reached a steady state both for PFCAs $>\mathrm{C}_{11}$ (PFUnA, PFDoA, PFTrDA) and PFOS and FOSA. However, in Lasier et al. (2011), L. variegatus 
333 PFHpA, PFOA, PFNA, and PFDA, although they were measured in sediment. This

334 could be explained by the difference in feeding habits between the two organisms

335 (Nogaro et al., 2009). In addition, chironomid growth during the accumulation phase is

336 not negligible, unlike for L. variegatus, which lost weight (because it went unfed), as

337 growth dilutes contamination. PFAS accumulation in chironomids was as effective

338 when exposure started at $2^{\text {nd }}$ instar as when it started at $4^{\text {th }}$ instar. PFASs concentrations

339 were the same between the end of E1 and E2 exposures (Table 1, Fig. 3). At the latter

340 stage, growth is more rapid than at previous stages (Péry et al., 2002). These results

341 suggest that the sole use of the $4^{\text {th }}$ instar in could be included in the design of future

342 experimental studies with this organism.

343 For PFTrDA, PFUnA, PFOS, and FOSA, accumulation data obtained in the present

344 study fit an exponential rise model well (Eq. 1), with $\mathrm{R}^{2}$ values ranging from 0.99

345 (PFOS) to 0.97 (PFUnA). Equation (1) supports either a classical two-compartment

346 partition model (Higgins et al., 2007; Landrum, 1989) or a more sophisticated

347 adsorption-like accumulation model (Liu et al., 2011). Model parameter $a$ is related to

348 the exposure concentration $\left(\mathrm{C}_{\mathrm{sed}-\mathrm{oc}}\right)$ and uptake and depuration rates $\left(\mathrm{k}_{\mathrm{u}}\right.$ and $\mathrm{k}_{\mathrm{e}}$

349 respectively).

350 Model parameter $b$ is related to the elimination rate $\left(\mathrm{k}_{\mathrm{e}}\right)$. As chironomids grow during

351 the experiment, the elimination rate $\left(k_{e^{\prime}}\right)$ should be corrected according to Eq. (3)

352 (Spacie and Hamelink, 1985),

$$
k_{e}^{\prime}=k_{e}+g \quad \text { Eq. (3) }
$$

The complete two-compartment model includes a $\lambda$ term in order to account for

355 the chemical concentration decline in sediment. This term is set to 1 , as in eq. 1 , when

356 sediment concentrations do not vary significantly during the experiment (that is, if the 
357 flux from sediment to organisms is much lower than the overall compound mass in

358 sediment). This was the case in the current experiment (Table S5). In this case, equation

359 (1) can be solved easily, with $b$ being the apparent elimination rate $\left(k_{e}{ }^{\prime}\right.$ in $\left.\mathrm{h}^{-1}\right)$, and

$360 \quad a=\left(k_{u} / k_{e}\right)^{*} C_{\text {sed-oc }} \quad$ eq. (4)

361 with $k_{u}$ the uptake rate $\left(\mathrm{g}_{\mathrm{oc}} \cdot \mathrm{g}_{\mathrm{ww}} \cdot \mathrm{h}^{-1}\right)$ and $C_{\text {sed-oc }}$ the concentration in sediment normalized

362 to the organic carbon content (ng. $\mathrm{goc}^{-1}$ ).

363 Applying this approach, yields $\left(k_{u}, k_{e}\right.$, and $\left.k_{e^{\prime}}\right)$ were obtained for PFTrDA, PFUnA,

364 PFOS, and FOSA) (Table 3). These data are only informative because no depuration

365 data were available.

366 The adsorption-like model (Liu et al., 2011) was developed initially for an uptake

367 experiment from water. We assumed that it could also apply to accumulation from

368 sediment and food as in our study. Nevertheless, it cannot be solved without depuration

369 data because three variables are included in the terms $a$ and $b$ instead of two as in the

370 two-compartment model:

$371 a=\left(n * k_{u} * C_{s e d}\right) /\left(k_{u} * C_{s e d}+k_{e}\right)$

$b=k_{u} * C_{s e d}+k_{e}$

Eq. (6)

373 where $n$ is the number of adsorption sites.

\subsection{Contamination routes}

375 All compounds accumulated by the chironomids were detected in sediment. PFUnA,

376 PFOS, and 6:2 FTSA were also quantified in both pore and overlying water and

377 PFTrDA was detected in overlying water. In addition, some compounds, such as

378 PFUnA, PFOS, and FOSA, were found in food added $\left(\right.$ Tetramin $\left.^{\circledR}\right)$ to chironomids,

379 which did not affect accumulation in chironomids (i.e., the balance between 
380 accumulation and depuration) because these compounds were not detected in control

381 chironomids (PFAS concentrations <LDs).

382 These results therefore suggest that there are two contamination routes for the

383 PFASs, which differ according to the compounds. The contamination routes for

384 substances found in both pore water and sediment (particles) were via food and

385 tegument. For other compounds, found only in sediment, the contamination route was 386 only trophic.

387 These observations are supported by the growth data: larvae grew more in test

388 sediments than in the control setting, although they received the same quantity of

389 Tetramin $^{\circledR}$. These results indicate that larvae fed on organic carbon from the sediment

390 and thus may have absorbed the PFAS associated with particles. On the other hand, the

391 chironomid $\delta^{13} \mathrm{C}$ values were almost identical in test and control organisms, suggesting

392 that the proportion of C obtained by the larvae from the sediment was limited. This is

393 consistent with the findings reported by Goedkoop et al. (2006), which showed that

394 about $90 \%$ of the carbon intake was from added food. However, both $\delta^{13} \mathrm{C}$ and $\delta^{15} \mathrm{~N}$

395 values for Tetramin ${ }^{\circledR}$ were mean values because Tetramin ${ }^{\circledR}$ is a mixture of animal (fish,

396 crustaceans, mollusks) and plant (cereals) ingredients, each having its own isotopic

397 composition. Chironomids may feed selectively on certain components of the added

398 food (Goedkoop et al., 2006). Therefore, the observed chironomid $\delta^{13} \mathrm{C}$ signature may

399 be influenced by sediment organic carbon.

$400 \quad$ 5. Conclusion

401 Results from this study indicate that $C$. riparius accumulated four long-chain

402 perfluoroalkyl carboxylates (PFUnA, PFDoA, PFTrDA, and PFTeDA), a perfluoroalkyl

403 sulfonate (PFOS), a precursor (FOSA), and a fluorotelomer (6:2 FTSA) from sediment. 
404 No short-chain PFAS, detected mostly in water, were accumulated by chironomids. No

405 trends were observed for BSAFs, in contrast to studies by Higgins et al. (2007) and

406 Lasier et al. (2011). The contamination pathways appeared to be trophic (sediment

407 particles) and tegumentary (pore water) for PFUnA, PFOS, and 6:2 FTSA and only via

408 the trophic pathway for the other compounds. Growth data support the trophic

409 contamination route but isotopic data are difficult to interpret because of food added

410 during the experiments. PFUnA, PFTrDA, and PFOS data fit an exponential rise model;

411 apparent uptake and elimination constants can thus be proposed on the basis of the

412 classical partition model (Landrum, 1989; Spacie and Hamelink, 1985). Elimination

413 experiments should be conducted to determine the elimination kinetics experimentally

414 in this species.

\section{Acknowledgments}

416 This study was funded by the Rhone-Mediterranean and Corsica Water Agency and the

417 Rhone-Alpes Region within the Rhone ecological restoration plan. We thank Bernard

418 Motte (IRSTEA), Raphael Barlon, and the Centre d'Observation de l'Ile du Beurre team

419 (Condrieu, France) for their assistance during the sampling campaigns and chemical

420 laboratory analysis (UR MALY, IRSTEA Lyon-Villeurbanne) for monitoring the

421 physicochemical characterization of sediment, and Linda Northrup for copyediting the

422 text as well as two anonymous reviewers for their constructive remarks.

\section{References}

424 AFNOR, 1994. Determination of kjekldahl nitrogen - Method after mineralization with 425 selenium Water quality.

426 AFNOR, 2000. Determination of dry residue and water content Characterization of 427 sludges.

428 AFNOR, 2007. Determination of loss on ignition in waste, sludge and sediments 429 Characterization of waste.

430 AFNOR, 2010. Determination of the toxicity of fresh water sediments to Chironomous

431 riparius - Part 1 : natural sediments Water quality 
432 Ahrens, L., Yamashita, N., Yeung, L.W.Y., Taniyasu, S., Horii, Y., Lam, P.K.S., 433 Ebinghaus, R., 2009. Partitioning Behavior of Per- and Polyfluoroalkyl Compounds 434 between Pore Water and Sediment in Two Sediment Cores from Tokyo Bay, Japan. Environmental Science \& Technology 43, 6969-6975. Armitage, J., Cousins, I.T., Buck, R.C., Prevedouros, K., Russell, M.H., Macleod, M., Korzeniowski, S.H., 2006. Modeling global-scale fate and transport of perfluorooctanoate emitted from direct sources. Environmental Science and Technology 40, 6969-6975.

440 Armitage, P.D., Cranston, P.S., Pinder, L.C.V., 1995. The Chironomidae: Biology and 441 Ecology of Non-Biting Midges, first ed. Chapman and Hall, London.

442 Ballesteros-Gómez, A., Rubio, S., van Leeuwen, S., 2010. Tetrahydrofuran-water 443 extraction, in-line clean-up and selective liquid chromatography/tandem mass 444 spectrometry for the quantitation of perfluorinated compounds in food at the low picogram per gram level. Journal of Chromatography A 1217, 5913-5921.

Bao, J., Jin, Y., Liu, W., Ran, X., Zhang, Z., 2009. Perfluorinated compounds in sediments from the Daliao River system of northeast China. Chemosphere 77, 652-657. Bao, J., Liu, W., Liu, L., Jin, Y., Ran, X., Zhang, Z., 2010. Perfluorinated compounds in urban river sediments from Guangzhou and Shanghai of China. Chemosphere 80, 123130.

Benskin, J.P., Ikonomou, M.G., Gobas, F.A.P.C., Woudneh, M.B., Cosgrove, J.R., 2012. Observation of a Novel PFOS-Precursor, the Perfluorooctane Sulfonamido Ethanol-Based Phosphate (SAmPAP) Diester, in Marine Sediments. Environmental Science \& Technology 46, 6505-6514. Brooke, L.T., Ankley, G.T., Call, D.J., Cook, P.M., 1996. Gut content weight and clearance rate for three species of freshwater invertebrates. Environmental Toxicology and Chemistry 15, 223-228.

458 Clara, M., Gans, O., Weiss, S., Sanz-Escribano, D., Scharf, S., Scheffknecht, C., 2009. Perfluorinated alkylated substances in the aquatic environment: An Austrian case study. Water Research 43, 4760-4768.

Dauchy, X., Boiteux, V., Rosin, C., Munoz, J.F., 2012. Relationship between indusrial discharges and contamination of raw water ressources by perfluorinated compounds. Part I: Case study of a fluoropolymer manufacturing plant. Bull Environ Contam Toxicol 89, 525-530.

465 DuPont Zonyl FSE, 2008. Fluorotelomer Products in the Environment - An Update NFPA. http://www2.dupont.com/Capstone/en_US/index.html (April 24 2013).

Goedkoop, W., ÅKerblom, N., Demandt, M.H., 2006. Trophic fractionation of carbon and nitrogen stable isotopes in Chironomus riparius reared on food of aquatic and terrestrial origin. Freshwater Biology 51, 878-886.

Higgins, C.P., Field, J.A., Criddle, C.S., Luthy, R.G., 2005. Quantitative determination of perfluorochemicals in sediments and domestic sludge. Environmental Science and Technology 39, 3946-3956.

Environmental Science and Technology 40, 7251-7256.

475 Higgins, C.P., McLeod, P.B., Macmanus-Spencer, L.A., Luthy, R.G., 2007.

476 Bioaccumulation of perfluorochemicals in sediments by the aquatic oligochaete

477 Lumbriculus variegatus. Environmental Science and Technology 41, 4600-4606. 
478 Houde, M., De Silva, A.O., Muir, D.C.G., Letcher, R.J., 2011. Monitoring of

479 Perfluorinated Compounds in Aquatic Biota: An Updated Review. Environmental

480 Science \& Technology 45, 7962-7973.

481 Houde, M., Martin, J.W., Letcher, R.J., Solomon, K.R., Muir, D.C.G., 2006. Biological

482 monitoring of polyfluoroalkyl substances: A review. Environmental Science and

483 Technology 40, 3463-3473.

484 Jeon, J., Kannan, K., Lim, H.K., Moon, H.B., Kim, S.D., 2010a. Bioconcentration of

485 perfluorinated compounds in blackrock fish, Sebastes schlegeli, at different salinity

486 levels. Environmental Toxicology and Chemistry 29, 2529-2535.

487 Jeon, J., Kannan, K., Lim, H.K., Moon, H.B., Ra, J.S., Kim, S.D., 2010 b.

488 Bioaccumulation of perfluorochemicals in pacific oyster under different salinity 489 gradients. Environmental Science and Technology 44, 2695-2701.

490 Kannan, K., Tao, L., Sinclair, E., Pastva, S.D., Jude, D.J., Giesy, J.P., 2005.

491 Perfluorinated compounds in aquatic organisms at various trophic levels in a Great

492 Lakes food chain. Archives of Environmental Contamination and Toxicology 48, 559-

493566.

494 Kelly, B.C., Ikonomou, M.G., Blair, J.D., Surridge, B., Hoover, D., Grace, R., Gobas,

495 F.A.P.C., 2009. Perfluoroalkyl contaminants in an arctic marine food web: Trophic

496 magnification and wildlife exposure. Environmental Science and Technology 43, 4037-

4974043.

498 Labadie, P., Chevreuil, M., 2011. Partitioning behaviour of perfluorinated alkyl

499 contaminants between water, sediment and fish in the Orge River (nearby Paris,

500 France). Environmental Pollution 159, 391-397.

501 Landrum, P.F., 1989. Bioavailability and toxicokinetics of polycyclic aromatic

502 hydrocarbons sorbed to sediments for the amphipod Pontoporeia hoyi. Environmental

503 Science \& Technology 23, 588-595.

504 Lasier, P.J., Washington, J.W., Hassan, S.M., Jenkins, T.M., 2011. Perfluorinated

505 chemicals in surface waters and sediments from northwest Georgia, USA, and their

506 bioaccumulation in Lumbriculus variegatus. Environmental Toxicology and Chemistry

507 30, 2194-2201.

508 Lindstrom, A.B., Strynar, M.J., Libelo, E.L., 2011. Polyfluorinated Compounds: Past,

509 Present, and Future. Environmental Science \& Technology 45, 7954-7961.

510 Liu, C., Gin, K.Y.H., Chang, V.W.C., Goh, B.P.L., Reinhard, M., 2011. Novel

511 Perspectives on the Bioaccumulation of PFCs - the Concentration Dependency.

512 Environmental Science \& Technology 45, 9758-9764.

513 Loi, E.I.H., Yeung, L.W.Y., Taniyasu, S., Lam, P.K.S., Kannan, K., Yamashita, N.,

514 2011. Trophic Magnification of Poly- and Perfluorinated Compounds in a Subtropical

515 Food Web. Environmental Science \& Technology 45, 5506-5513.

516 Martin, J.W., Whittle, D.M., Muir, D.C.G., Mabury, S.A., 2004. Perfluoroalkyl

517 contaminants in a food web from lake Ontario. Environmental Science \& Technology

518 38, 5379-5385.

519 Miège, C., Roy, A., Labadie, P., Budzinski, H., Le Bizec, B., Vorkamp, K.,

520 Tronczynski, J., Persat, H., Coquery, M., Babut, M., 2012. Occurrence of priority and

521 emerging organic substances in fishes from the Rhone river in the area of Lyon.

522 Analytical and Bioanalytical Chemistry, 2721-2735.

523 Myers, A.L., Crozier, P.W., Helm, P.A., Brimacombe, C., Furdui, V.I., Reiner, E.J.,

524 Burniston, D., Marvin, C.H., 2012. Fate, distribution, and contrasting temporal trends of 
perfluoroalkyl substances (PFASs) in Lake Ontario, Canada. Environment International 44, 92-99.

Nakata, H., Kannan, K., Nasu, T., Cho, H.S., Sinclair, E., Takemura, A., 2006. Perfluorinated contaminants in sediments and aquatic organisms collected from shallow water and tidal flat areas of the Ariake Sea, Japan: Environmental fate of

530 perfluorooctane sulfonate in aquatic ecosystems. Environmental Science and

531 Technology 40, 4916-4921.

Nania, V., Pellegrini, G.E., Fabrizi, L., Sesta, G., Sanctis, P.D., Lucchetti, D., Pasquale, M.D., Coni, E., 2009. Monitoring of perfluorinated compounds in edible fish from the Mediterranean Sea. Food Chemistry 115, 951-957.

535 Nogaro, G., Mermillod-Blondin, F., Valett, M.H., François-Carcaillet, F., Gaudet, J.P.,

536 Lafont, M., Gibert, J., 2009. Ecosystem engineering at the sediment-water interface:

537 Bioturbation and consumer-substrate interaction. Oecologia 161, 125-138.

538 OECD, 2004. Sediment - Water Chironomid Toxicity Test Using Spiked Sediment, 539 OECD Guidelines for the testing of chemicals, pp. 1-21.

540 Péry, A.R.R., Mons, R., Flammarion, P., Lagadic, L., Garric, J., 2002. A modeling approach to link food availability, growth, emergence, and reproduction for the midge Chironomus riparius. Environmental Toxicology and Chemistry 21, 2507-2513. Prevedouros, K., Cousins, I.T., Buck, R.C., Korzeniowski, S.H., 2006. Sources, fate and transport of perfluorocarboxylates. Environmental Science and Technology 40, 32. R Development Core Team, 2013. R: A language and environment for Statistical computing, in: R Foundation for Statistical Computing (Ed.), Vienna. Renner, R., 2006. The long and the short of perfl uorinated replacements. Environmental Science and Technology, 12-13. Spacie, A., Hamelink, J.L., 1985. Bioaccumulation, in: Rand, G.M., Petrocelli, S.R. (Eds.), Fundamentals of Aquatic Toxicology, pp. 495-519. chemicals in digested sewage sludges in Switzerland. Environmental Pollution 159, 654.

554 Theobald, N., Caliebe, C., Gerwinski, W., Hühnerfuss, H., Lepom, P., 2012. Occurrence 555 of perfluorinated organic acids in the North and Baltic Seas. Part 2: distribution in 556 sediments. Environmental Science and Pollution Research, 1-12.

557 Thompson, J., Roach, A., Eaglesham, G., Bartkow, M.E., Edge, K., Mueller, J.F., 2011. 558 Perfluorinated alkyl acids in water, sediment and wildlife from Sydney Harbour and 559 surroundings. Marine Pollution Bulletin.

560 Tomy, G.T., Budakowski, W., Halldorson, T., Helm, P.A., Stern, G.A., Friesen, K., 561 Pepper, K., Tittlemier, S.A., Fisk, A.T., 2004. Fluorinated organic compounds in an 562 Eastern arctic marine food web. Environmental Science and Technology 38, 6475-6481. 563 Vatan, A., 1967. Manuel de sédimentologie. Technip, Paris.

564 Zushi, Y., Tamada, M., Kanai, Y., Masunaga, S., 2010. Time trends of perfluorinated 565 compounds from the sediment core of Tokyo Bay, Japan (1950s-2004). Environment 566 and Pollution 158, 756. 
570 Table 1: PFAS concentrations in chironomids at the end of E1 and E2 exposures (ng. $\mathrm{g}^{-1}$ ww). E1 with standard deviation $(n=3)$ and E2 with analytical error calculation relative to spiked samples (Table S3). PFTeDA "trace" means that concentrations were between LD and LQ.

575 Table 2: $\mathrm{BSAF}_{\mathrm{ww}}\left(\mathrm{g}_{\mathrm{oc}} \cdot \mathrm{g}_{\mathrm{ww}}{ }^{-1}\right)$ for chironomids and for Lumbriculus variegatus (Higgins et al., 2007; Lasier et al., 2011); n.d, not detected, *PFTeDA, as guidelines only (because LD < PFTeDA concentrations in chironomids < LQ).

Figure 1: Study site of the Rhône River, France. BER = Beurre Island, Plant = PFAS production plant. The river runs from north to south.

Figure 2: Kinetics of PFASs accumulation in fourth instar larvae of C. riparius, in the E2 experiment. Left, PFSAs; right, PFCAs (PFTeDA concentrations were between LD and LQ). Error bars represent the analytical error estimated from the relative standard deviation of triplicate recovery rate tests performed on spiked samples (Table S3).

Figure 3: PFCA accumulation in E1 (left, LD < PFTeDA concentrations < LQ) and E2

591 (right) experiments. Error bars represent the analytical error estimated from the relative 592 standard deviation of triplicate recovery rate tests performed on spiked samples (Table

593 S3); on the right graph they represent the standard deviation between three replicates ( $n$ $594=3)$. 
596 Figure 4: Partitioning between different compartments: green represents PFASs in food

597 or from a food source, and brown, in the same manner, for sediment. For chironomids,

598 the blue frames represent both sediment (brown) and pore water (blue) sources for

599 PFASs.

600

601

602 
Table 1 : PFAS concentrations in chironomids at the end of E1 and E2 exposures

\begin{tabular}{|l|c|c|}
\hline Compounds & $\begin{array}{l}\text { PFASs in chironomids } \\
\text { at the end of E1 (ng.g } \\
1 \\
{ }^{-} w \text { w) }\end{array}$ & $\begin{array}{l}\text { PFASs in chironomids at } \\
\text { the end of E2 }\left(\mathrm{ng}^{-1} \mathrm{~g}^{-1} \mathrm{ww}\right)\end{array}$ \\
\hline PFUnA & $0.79 \pm 0.10$ & $0.80 \pm 0.08$ \\
\hline PFDoA & $0.11 \pm 0.01$ & $0.14 \pm 0.01$ \\
\hline PFTrDA & $1.71 \pm 0.42$ & $2.42 \pm 0.17$ \\
\hline PFTeDA trace & $0.05 \pm 0.001$ & $0.08 \pm 0.02$ \\
\hline PFOS & $0.16 \pm 0.02$ & $0.13 \pm 0.02$ \\
\hline FOSA & $0.05 \pm 0.01$ & $0.05 \pm 0.02$ \\
\hline $6: 2$ FTSA & $0.07 \pm 0.03$ & $0.08 \pm 0.005$ \\
\hline
\end{tabular}


Table 2: $\mathrm{BSAF}_{\mathrm{ww}}\left(\mathrm{g}_{\mathrm{oc}} \cdot \mathrm{g}_{w w}{ }^{-1}\right)$

\begin{tabular}{|l|c|c|c|c|}
\hline Compounds & $\begin{array}{l}\text { Fluorinated } \\
\text { carbon } \\
\text { number }\end{array}$ & $\begin{array}{l}\text { BSAF }_{\text {ww }} \\
\text { chironomid }\end{array}$ & $\begin{array}{l}\text { BSAF }_{\text {ww }} \\
\text { Higgins et } \\
\text { al., 2007 }\end{array}$ & $\begin{array}{l}\text { BSAF }_{\text {ww }} \\
\text { Lasier et al., } \\
\mathbf{2 0 1 1}\end{array}$ \\
\hline PFUnA & 10 & 0.020 & $0.44 \pm 0.11$ & $0.29, C V=40$ \\
\hline PFDoA & 11 & 0.004 & $0.45 \pm 0.08$ & $0.34, C V=40$ \\
\hline PFTrDA & 12 & 0.042 & n.d & $0.62, C V=44$ \\
\hline PFTeDA* & 13 & 0.004 & n.d & $0.63, C V=47$ \\
\hline PFOS & 8 & 0.023 & $0.83 \pm 0.20$ & $0.49, C V=50$ \\
\hline $6: 2$ FTSA & 6 & 0.018 & n.d & n.d \\
\hline FOSA & 8 & 0.098 & n.d & n.d \\
\hline
\end{tabular}


Table 3: Model parameters

\begin{tabular}{|c|c|c|c|c|}
\hline Compounds & $\mathrm{a}$ & $\mathrm{ku}$ & $\mathrm{ke}(\mathrm{b})$ & $\mathrm{ke}$ \\
\hline PFUnA & $0.83 \pm 0.03$ & 0,0009 & $0.04 \pm 0.01$ & 0,03 \\
\hline PFTrDA & $2.56 \pm 0.11$ & 0,0015 & $0.03 \pm 0.01$ & 0,02 \\
\hline PFOS & $0.14 \pm 0.008$ & 0,0009 & $0.04 \pm 0.01$ & 0,03 \\
\hline FOSA & $0.06 \pm 0.01$ & 0,0022 & $0.02 \pm 0.01$ & 0,01 \\
\hline
\end{tabular}


Figure 1 : Study site

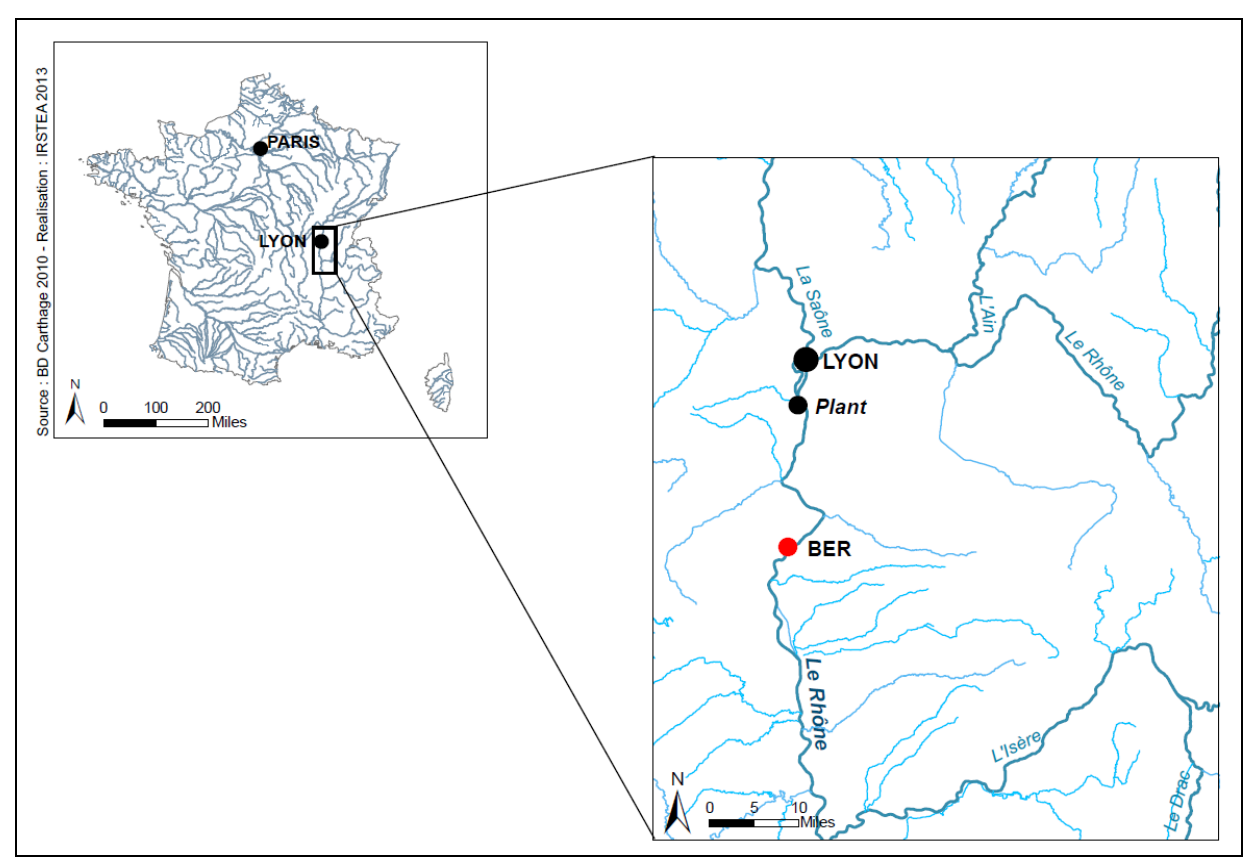


Figure 2: Kinetics of PFAS accumulation in fourth instar larvae of Chironomus riparius.
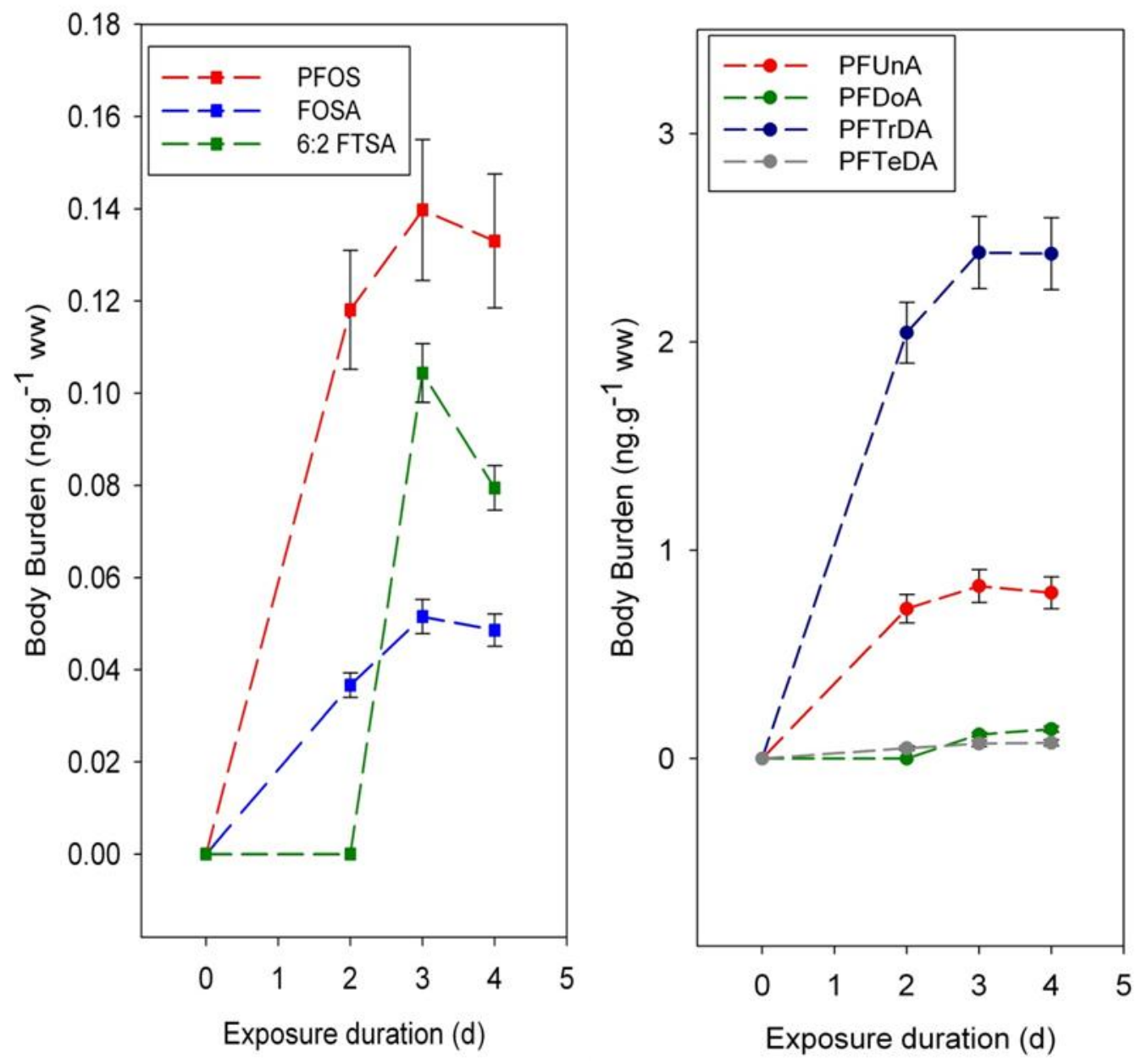
Figure 3: PFCA accumulation in E1 (left) and E2 (right) experiments.
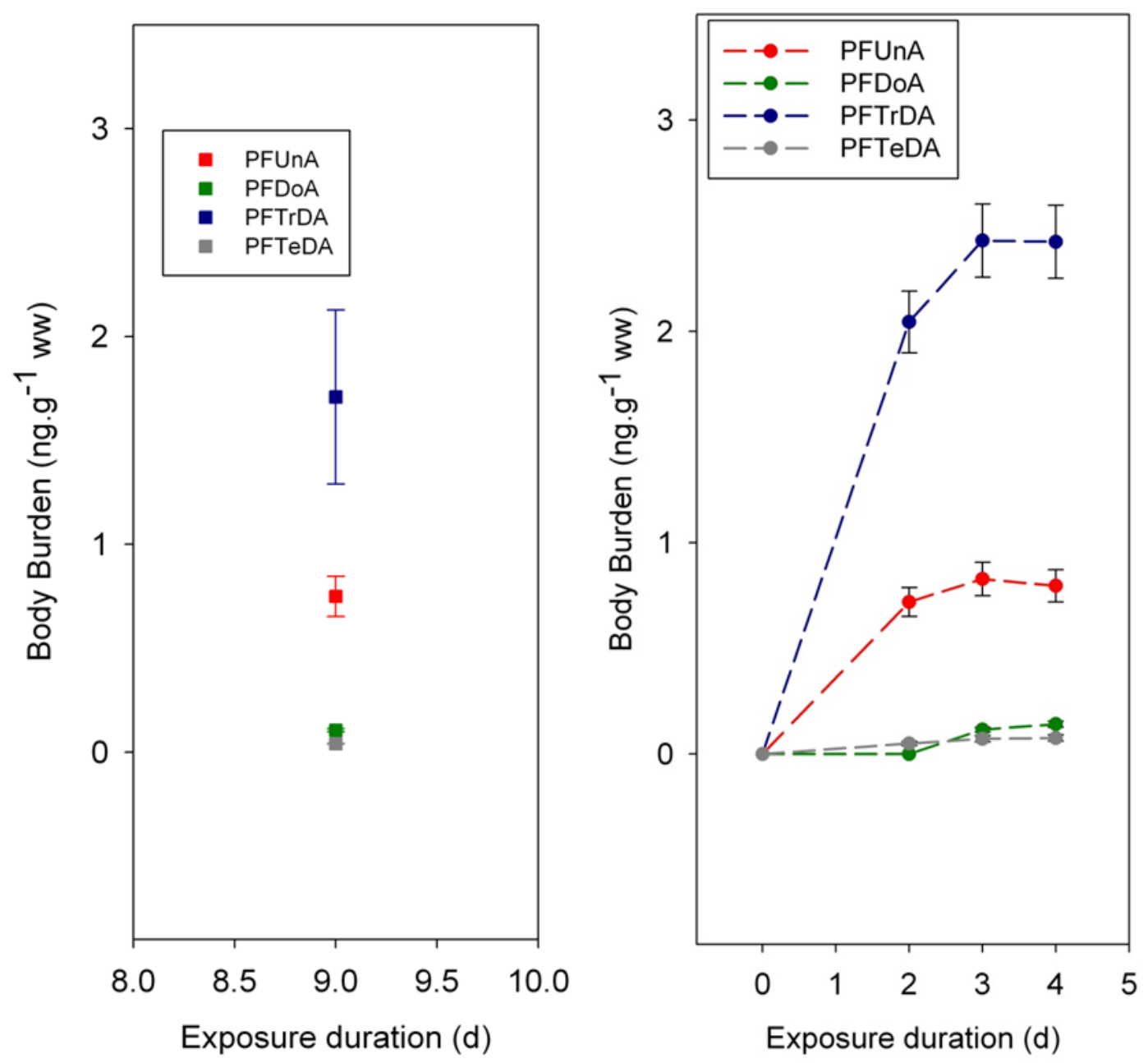
Figure 4: Partition between different compartments

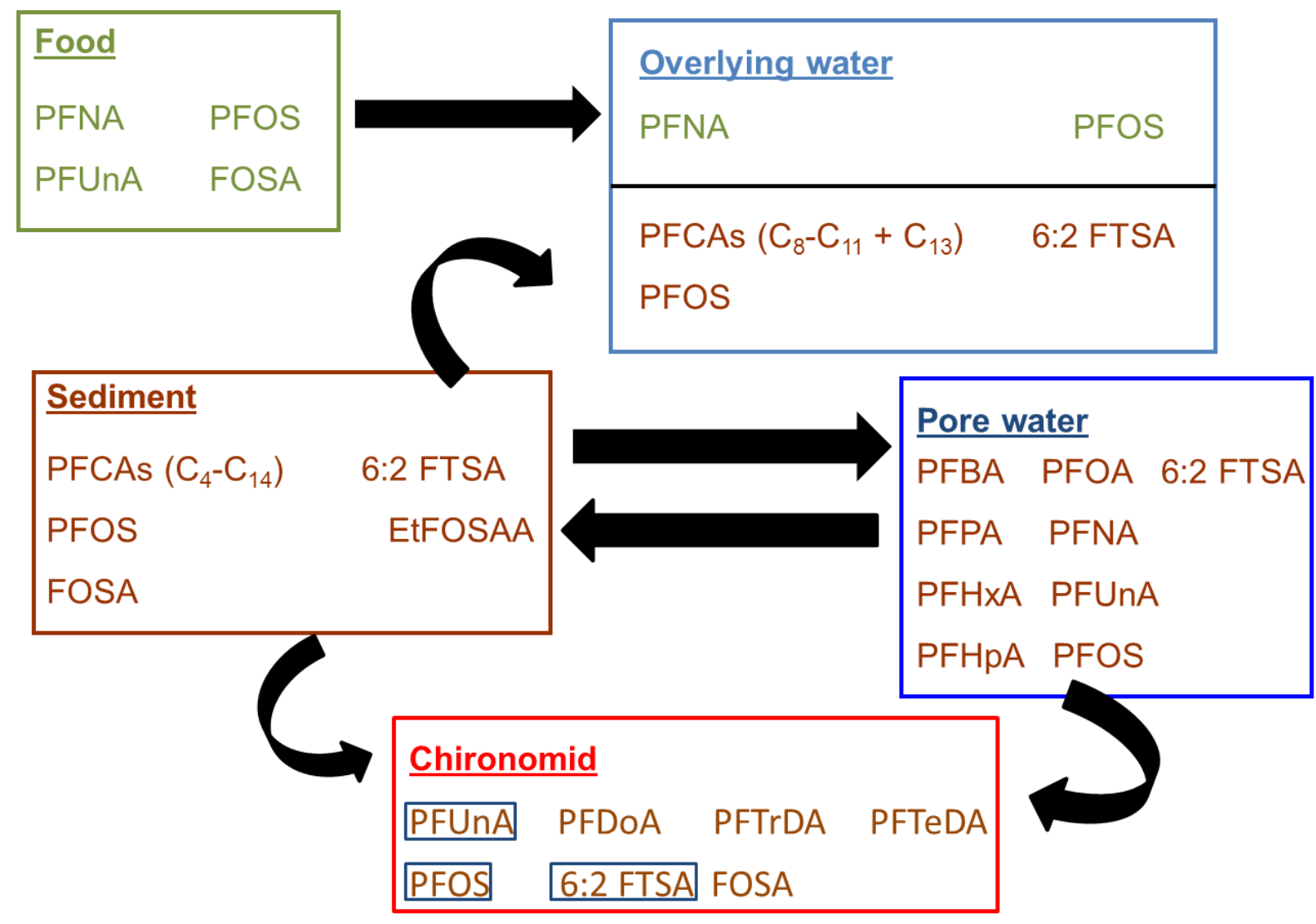


